\title{
Eugênio Gudin: As Controvérsias do Neoliberalismo Caboclo*
}

\author{
Eugênio Gudin: The Controversies of Caboclo Neoliberalism
}

MARIA ANGÉLICA BORGES**

\begin{abstract}
RESUMO: Este artigo examina a produção teórica de Eugênio Gudin que expressa sua nova postura liberal, que destaca sua oposição a Roberto Simonsen, a teoria do desenvolvimento econômico do Cepal, Marx e seus seguidores. Gudin reconheceu Karl Marx como o maior inimigo do capitalismo. Ele atribuiu ao pensador a criação do conceito de capitalismo com conotações históricas. Negando radicalmente esse conteúdo e equilibrando a concepção do caráter natural e eterno desse sistema, ele se concentrou no capitalismo como um sistema de produção que se conecta harmonicamente à democracia. Ele trabalhou com o par de conceitos: economia, mercado e democracia como antítese do planejamento e do totalitarismo, estruturando o discurso que enfatiza o plano geral abstrato, desconsiderando uma análise histórica concreta de cada caso específico. Consequentemente, todo aspecto que não se encaixa nesse par é considerado antidemocrático e intervencionista, como uma negação equivalente ao ideal humano, às vezes que deve ser evitado ou mesmo destruído. PALAVRAS-CHAVE: História do pensamento econômico; Gudin; neoliberalismo.
\end{abstract}

ABSTRACT: This article examines Eugênio Gudin's theorical production that express his new liberal posture, which highlights his opposition to Roberto Simonsen, Cepal's economic development theory, Marx and followers. Gudin recognized Karl Marx as the biggest enemy of capitalism. He attributed to the thinker the creation of the concept of capitalism with historical connotations. Radically denying this content and balancing the conception of the natural and eternal character of this system, he focused on capitalism as a production system which connects itself harmonically with democracy. He worked with the pair of concepts: economy market and democracy as an antithesis of planning and totalitarism, structuring the discourse that stress the abstract general plan, disregarding a concrete-historical analysis for each specific case. Consequently, every aspect that does not fit that pair is considered undemocratic and interventionist, as an equivalent denial of the human ideal, sometimes that should be avoided, or even destroyed.

KEYWORDS: History of economic thought; Gudin; neoliberalism.

JEL Classification: B31.

\footnotetext{
* Este artigo reproduz algumas das ideias centrais da tese de doutorado defendida no Programa de Estudos Pós-Graduados em História da PUC/SP (1995).

* Professora de Economia e Diretora da Faculdade de Economia e Administração da Pontifícia Universidade Católica de São Paulo - PUC/SP, São Paulo/SP, Brasil. E-mail:
} 


\section{INTRODUÇÃO: AS NUANÇAS DO PENSAMENTO GUDINIANO}

Não é suficiente que o pensamento tenda para a
realidade; a realidade mesma deve tender para o
pensamento.

Marx

A obra de Eugênio Gudin ao longo de quase seis décadas é, até os dias de hoje, referência para o pensamento neoliberal no país. A ciência econômica nasce como disciplina particular no bojo do modo de produção capitalista. Esse nascimento dá-se a partir da divisão do trabalho também no plano do saber, gerado pela complexidade do ser social, que necessitava dar conta de um mundo em desenvolvimento. Mas essa ciência teve uma longa pré-história. Desde os registros mudos - pelos quais os arqueólogos fazem as pedras falarem -, como também nos primeiros documentos da era literária, estão presentes as indagações e buscas de respostas para as questões econômicas.

As respostas formuladas refletem o próprio desenvolvimento contraditório da história social. E, após o capitalismo industrial, é marcante o grau de expansão desse desenvolvimento. Sendo assim, houve a necessidade da criação de um discurso próprio ao tecido econômico.

A expansão do capitalismo gerou caminhos específicos de sua construção em cada local. Porém, esses caminhos não negam sua origem; ao contrário, trazem a marca do universal, reproduzindo-o com suas especificidades. É um movimento crescente de totalização, no qual todo e partes interagem a partir de pólos hegemônicos e elos dependentes.

Ao procurarmos as primeiras formulações mais sistemáticas sobre a ciência econômica no Brasil, deparamo-nos com a figura singular de Eugênio Gudin. Várias pistas indicavam-nos ser o seu estudo bastante revelador do ser histórico brasileiro e da gênese do estudo de economia no país como objeto do conhecimento. E assim, como na gênese da ciência econômica no século XVIII, aqui também, o desenvolvimento industrial determinou o incremento da teoria econômica, porém, com cores próprias.

Gudin, nos seus textos, forneceu-nos a inspiração para a nossa tese de doutorado. Na sua obra, encontramos os elementos necessários para o estudo do capitalismo nas suas diferentes fases, assim como a sua ligação com a ciência econômica e seus matizes ideológicos no cenário nacional. Ao percorrermos a formação da ciência econômica no país, encontramos, no seu centro, a problemática da construção do capitalismo industrial embasando aquela gênese. Ao realizar um estudo, estávamos realizando o outro. Sua separação é quase impossível. E, em última instância, o que diferencia as linhas que abraçam o estudo da economia é a forma como ambas entendem a relação entre economia e realidade social. Isolada dentro do próprio objeto como fator econômico e autônomo em relação aos demais, ou como momento constitutivo da totalidade concreta em um movimento contraditó- 
rio onde determinante e determinado interagem e se influenciam. Gudin filia-se a primeira vertente. $\mathrm{O}$ autor em tela abraça o estudo da economia para compreender as crises vividas pelo capitalismo e, a partir daí, propor a inserção brasileira na economia internacional, segundo uma lógica de equilíbrio que respeita a Lei das Vantagens Comparativas, como fica patente nos seus textos desde o início de sua produção intelectual. Seus primeiros escritos datam dos anos 20 e sua busca incessante visa a expulsar a possibilidade de desequilíbrio estrutural do fator econômico. As crises existem, são reais, porém, localizadas fora da esfera da produção: quando lá chegavam, já tinham sido determinadas pelo fator político.

Partindo da ideia de que o capitalismo é uma técnica natural de produção, Gudin destaca seu caráter racional de gerir a economia. Essa racionalidade, que possui a sua própria dinâmica e não é dirigida, é cada vez mais aprimorada na evolução da humanidade.

Existe, porém, um movimento desigual no mundo em relação ao desenvolvimento desta técnica. Há países mais atrasados do que outros. E, no caso brasileiro, o atraso é patente. Gudin reconhece esse atraso, que, na sua obra, é entendido dentro do contexto da evolução natural do sistema. Somos mais jovens e temos mais chances de chegar lá. Chances que devem ser subordinadas à lógica natural do capital.

A maneira como será apresentada essa discussão traduz um esforço de síntese do tema capitalismo, seus desdobramentos ideológicos na vertente neoliberal na obra de Gudin e sua relação com a ciência econômica. Os textos utilizados para o estudo da obra do mestre dos economistas neoliberais foram selecionados segundo essa temática; como a produção intelectual do autor é vasta — composta ao redor de 2.000 títulos -, assumimos, como critério, o recorte a partir desse nosso tema. O eixo norteador da nossa abordagem é a posição de Gudin a respeito do capitalismo e sua relação com a teoria econômica. E, conforme ele avança nas suas colocações, delimitando as formas e discutindo as crises, apresentamos nossa análise da obra, procurando explicitá-la no plano da ideologia - entendida aqui na sua forma restrita ${ }^{1}$ — como prévia ideação das classes sociais nos seus conflitos.

Gudin forjou sua concepção de capitalismo temperada em várias atividades. Foi professor de economia, engenheiro, homem de empresa e ocupou vários cargos públicos. Todas essas etapas, é claro, influíram na sua visão de mundo, deixada por todos os lugares pelos quais passou.

Falar de Gudin e da sua concepção de capitalismo pressupõe registrar, mesmo que de forma aproximativa, todos esses elementos da sua formação.

Carioca, nascido em 1886, era descendente de negociantes franceses que chegaram ao Brasil na primeira metade do século XIX. Ainda jovem, formou-se engenheiro pela Escola Politécnica do Rio de Janeiro (1905).

\footnotetext{
${ }^{1}$ Ver, sobre a discussão da ideologia nas suas manifestações ampla e restrita, a obra de G. Lukács, “ II Problema dell'ldeologia", seção 3 do volume II de Per L”Ontologia Dell'Essere Sociale, versão italiana de Alberto Scarponi, a partir da cópia datilográfica da redação em alemão, preparada por Ferenc Bródy e Gábor Révai e revista por G. Lukács, Roma, Editori Riuniti, 1ª edição, 1981
} 
Após algumas experiências empresariais como engenheiro (inclusive ferroviário), chegou ao estudo sistemático da ciência econômica. Iniciou, já no final da década de 20 e começo dos anos 30, uma prática jornalística voltada à economia.

Essa trajetória inicial levou-o à cátedra de economia monetária e à colaboração na formação da primeira Faculdade de Economia do país. Formou uma escola de intelectuais e economistas que rezavam e rezam na cartilha neoliberal ${ }^{2}$.

Merece destaque sua passagem pelo Ministério da Fazenda. Apesar de nossa preocupação central ser a sua discussão do conceito de capitalismo, essa experiência revela nuanças que devem ser refletidas com maior profundidade. Gudin coloca em prática todas as suas concepções nesse breve período de atuação numa das esferas mais altas do poder público.

Investigamos os escritos de Eugênio Gudin desde a sua produção inicial até a sua conclusão, nos anos 80, produção expressa em livros, nos seus incontáveis artigos, conferências e discursos. Encontramos a maior parte do material já organizado pela Fundação Getúlio Vargas do Rio de Janeiro, em especial os livros e artigos publicados em revistas. Mas, assim mesmo, verificamos todo o material que diz respeito ao economista diretamente nas fontes, inclusive artigos de jornais que, mesmo compilados em livros, merecem tal cuidado.

Porém, chamou-nos a atenção o fato de a FGV/RJ ter cuidado tão bem do acervo do economista. Tal cuidado torna-se compreensível, uma vez que o nome de Gudin se confunde com o daquela instituição, onde viveu grande parte de seu tempo construindo e defendendo seus ideais, além de ter criado importantes revistas especializadas em Economia. Neste artigo, detalharemos alguns desses pontos.

\section{GUDIN: DO CAPITALISMO NATURALISTA À INSERÇÃO DA ECONOMIA BRASILEIRA NO CAPITALISMO MUNDIAL}

As primeiras obras de Eugênio Gudin versam sobre o capitalismo naturalista ${ }^{3}$, conceito-chave na obra do autor e que ressalta, principalmente, o funcionamento

\footnotetext{
${ }^{2}$ Exemplo disso é o número da Revista Digesto Econômico de agosto de 1983, que traz na capa o retrato de Roberto Campos. Na apresentação, Afif Domingos lembra que aquele número marca "um Digesto Econômico em nova fase. Ontem e hoje, na defesa da livre iniciativa". E que "mesmo totalmente reformulada, a revista conserva o propósito inarredável de lutar contra o avanço da estatização. Ela focaliza, nesta edição que marca a nova fase, as propostas do senador Roberto Campo s. Neste número tão especial é reproduzido o discurso de Roberto Campos da tribuna do Senado, dizendo não à moratória; e será a figura de Gudin evocada para dar corpo a sua mensagem: 'Aliás o único brasileiro que conheço, totalmente isento de culpa por nos ter advertido destemidamente no Tempo e na Hora, é o professor Eugênio Gudin, com a sua infinita sabedoria de quase um século de vida'”. Ver Digesto Econômico. São Paulo, número especial lançado em agosto de 1983, p. 7.

${ }^{3} \mathrm{O}$ regime econômico que no século XIX fez o progresso e a hegemonia da Europa foi o do capitalismo naturalista, que se desenvolveu à sombra da Economia Liberal e da Civilização Industrial.” Gudin, E. “Aspecto Econômico do Corporatismo Brasileiro" in Almanak Laemmert. Rio de Janeiro, p. 27.
} 
da economia natural de mercado do século XIX, modelo de desenvolvimento e harmonia, trazendo à frente a figura principal da Inglaterra.

Encontrado o tipo ideal a ser perseguido, o capitalismo inglês, Gudin norteou sua análise segundo esse modelo, que passou a ser a bússola indicadora do que era positivo ou negativo na economia, tanto no século XIX como no século XX.

O papel da economia brasileira voltada para o mercado externo, como exportadora de produtos primários, deveria ser aquele que tínhamos em relação à Inglaterra no século XIX. O construto ideal do século XIX sinalizava, juntamente com a figura principal da Inglaterra (o sol), o nosso papel de satélite. O mundo do equilíbrio perfeito é aquele onde realizávamos a nossa vocação agrária. ${ }^{4}$

Em todos os debates travados por Gudin, a Inglaterra fazia-se presente como o baluarte de glorificação do capitalismo naturalista; e o Brasil tinha assegurado seu lugar junto a ela como exportador. É a eternização desse quadro que inspira Gudin e o que foge a esse modelo merece a sua reprovação.

Gudin não almejou sermos um dia como a Inglaterra, mas desejava que esta cumprisse sempre o mesmo papel dentro do capitalismo, para que pudéssemos cumprir o nosso. Quando os EUA a substituíram na liderança mundial, o seu erro maior foi não manter esse papel. Ou seja, ser o maior comprador mundial dos países primário-exportadores. O problema não foi a substituição de uma nação por outra, mas sim a mudança nos papéis.

O economista carioca jamais abandonou o conceito de capitalismo como regime natural, equilibrado e racional de produção. Ao longo de sua volumosa obra, desde o início até os últimos escritos, esse pressuposto sempre esteve presente. Contemplou a separação do econômico, enquanto momento autônomo da realidade social, das demais manifestações do ser social. O capitalismo naturalista se põe como instância própria, que não se relaciona com as outras instâncias, ou melhor, não deve se relacionar. Pois, quando o encontro das instâncias acontece, o resultado é prejudicial para a economia. Visto que a economia realiza naturalmente a essência humana -através da economia de mercado -, quando o interesse privado é satisfeito, o interesse global também acontece simultaneamente. Gudin parte do pressuposto de que o egoísmo racional viabiliza, através das trocas, o bem comum, mesmo que a teleologia seja o interesse individual, já que a realização da "minha riqueza" tem, necessariamente, de ir ao encontro da satisfação da necessidade do outro. Logo, na economia, o mundo da vida privada dá conta das suas contradições, pois os diferentes egoísmos se compensam. O princípio do equilíbrio está posto e será mantido com o policiamento do sistema. As irresoluções do capitalismo não o colocam em xeque, fazem parte de sua evolução natural, pois as positividades são ainda maiores que os males do sistema. Consequentemente, o autor enfileira-se aos teóricos que posteriormente viram no capitalismo o "fim da história". A humanidade encontrou a técnica mais racional da atividade produtiva: a economia

\footnotetext{
${ }^{4}$ Exatamente sobre a interpretação da vocação agrária da qual Gudin foi um prócer, ver o ensaio de Bresser-Pereira, L. C. “Seis Interpretações sobre o Brasil” in Revista Dados vol. 25, n 3, 1983.
} 
de mercado. Cabe-lhe agora, cada vez mais, aperfeiçoá-la. Para uma breve ilustração, vamos dar voz ao autor em um texto da segunda metade da década de 1930: "O regime econômico que no século XIX fez o progresso e a hegemonia da Europa foi o do capitalismo naturalista, que se desenvolveu à sombra da Economia Liberal e da Civilização Industrial". ${ }^{5}$

Tendo como mola-mestra do seu ideário a concepção naturalista da economia, Gudin concebe o mecanismo de funcionamento da sociedade brasileira, a relação Estado-economia e a inserção do país no mercado mundial, sendo este último ponto o fulcro de suas preocupações e o maior responsável pela atualidade do pensamento do autor. Sempre que, nos momentos de crise, os rearranjos da divisão internacional do trabalho colocam na ordem do dia a nova correlação das forças do capitalismo e a disputa em torno da acumulação do capital se exarceba, as diferentes correntes que representam os diferentes interesses se armam e no cenário nacional Gudin é relembrado. ${ }^{6}$

Economista autodidata, debruçou-se sobre as questões econômicas já na maturidade, aos 40 anos de idade, e, após esse período, produziu intensamente nesse campo até o final de sua trajetória centenária. Foi o representante do Brasil na Conferência de Bretton Woods em 1944.

Gudin gerou, em torno de sua figura, dois tipos de interlocutores: críticos virulentos e adeptos ferrenhos. Não admitia, assim como não comportava, o meio termo quando se tratava da defesa da economia de mercado. Debateu com o marxismo e, na contraposição, reafirmou o capitalismo naturalista. Utilizou esse debate para confirmar a sua filiação a um segmento de nossa elite: o setor ligado à produção primário-exportadora.

Expressando a postura do ideólogo neoliberal, desde a década de 1930, dialogou com o marxismo e seus seguidores. Contrário às ideias marxistas — sendo que no seu ideário essas ideias se misturam à experiência do socialismo real — assim como à intervenção do Estado na economia, Gudin engloba essas duas iras em um único fenômeno e volta-se contra o regime russo, que "de 'comunista' só tem o cartaz. O comunismo, no sentido primário que se lhe dá, de repartir com os pobres o que é dos ricos, nada mais é do que uma ilusão grosseira". ${ }^{7}$ E prossegue nessa linha de argumentação, sendo que esse ponto, para nós, tem importância destacada: "O verdadeiro regime econômico dos Soviets é o do mais completo capitalismo de Estado. O operário e o camponês russos vivem, ainda que sob aspectos diversos, na mesma miséria e escravidão a que já estavam habituados, senão pior. Com uma só

\footnotetext{
${ }^{5}$ E. Gudin, “Aspecto Econômico do Corporatismo Brasileiro” in Almanak Laemmert. Rio de Janeiro, 1938 , p. 27.

${ }^{6}$ Lembramos com relação a esse ponto a discussão de Pérsio Arida, com relação à temática da retórica na economia, sobre reinventar a tradição. Ver Arida, P. "A História do Pensamento Econômico como Teoria e Retórica” in Rego, José Márcio (org.) Revisão da Crise: Metodologia e Retórica n.1 História do Pensamento Econômico. São Paulo, Bienal, 1991, pp. 36-7.

${ }^{7}$ E. Gudin, Estatização de nossa economia, Carta Mensal. Rio de Janeiro, 9: 3-25, ser. 1957 (Comentários à Conferência - pp. 15-25), p. 19.
} 
diferença: é que em vez de múltiplos capitalistas de outros tempos, o capitalista de hoje é um só: o Estado". ${ }^{8}$ De acordo com essa passagem, o autor afirma que a forma de organização da União Soviética é o capitalismo de Estado e, por ser estatal, tal forma de ser capitalista é ineficiente. Gudin não aborda a concepção marxiana de Estado, simplesmente rotula o Capitalismo de Estado na União Soviética como a viabilização da teoria marxiana. Não existe, na obra do autor, o enfrentamento das questões centrais sobre o Estado discutidas pelo marxismo; ao contrário, ele pratica a guerra do silêncio com relação a essa problemática.

Gudin via no filósofo alemão um dos grandes inimigos do capitalismo. Atribuiu a esse pensador a criação do conceito capitalismo com conotações históricas. Negou esse conteúdo radicalmente, contrapondo a conceituação do caráter natural e eterno desse sistema. Contemplou o capitalismo como o sistema de produção que se coaduna harmonicamente com a democracia. Trabalhou com o par economia de mercado/democracia como antítese de planejamento/totalitarismo, construindo um discurso que privilegia o plano geral abstrato, sem uma análise históricoconcreta para cada caso específico. Consequentemente, tudo o que não se encaixa naquele par é antidemocrático e intervencionista, equivalendo à negação do ideal humano, portanto, devendo ser evitado, ou melhor, destruído.

Eugênio Gudin enriquece o debate que mantém com o marxismo encontrando no Estado providencial, ou welfare state, um porto seguro para desdobrar a sua posição. Não discute o welfare state a partir de seus pressupostos, muito menos apresenta uma análise crítica de seu significado. Habilmente, utiliza-o como prova da superação definitiva do marxismo como alternativa ao capitalismo.

Não enfrenta profundamente essa problemática. Não questiona se esta forma de organizar o capitalismo coloca em xeque a sua proposta do novo liberalismo, não opina sobre a relação entre Estado e economia no welfare state, pois se enfrentasse esse ângulo da discussão, segundo o que analisamos do discurso gudiniano, tornaria esse exemplo imprestável para os seus propósitos.

Portanto, comentando essa proposta pela franja, utiliza-a como demonstração do fracasso da análise de Marx. O conceito de welfare state, para o autor, só tem a finalidade, de desmoralizar a proposta do filósofo alemão. Lembrando Hayek, frisa: "Disse o eminente e conhecido Professor Hayek... que 'o socialismo está morto; foi substituído pelo Estado Providencial (Welfare State)'. A supressão da propriedade privada dos meios de produção é um objetivo superado". ${ }^{9}$ Cumprido o papel de questionar a proposta marxiana, o economista autodidata protege-se de possíveis entusiasmos em relação ao Estado providencial e lembra o princípio capitalista da concorrência simbolizado no par desafio estímulo: "Não há hoje, em país algum do mundo, partido político que deixe de incluir, em maior ou menor grau, a assistência social em seu programa. O que há são divergências quanto à

\footnotetext{
${ }^{8}$ Idem, ibidem.

${ }^{9}$ E. Gudin, Inflação, Importação exportação: Café, Crédito, Desenvolvimento, Industrialização, $2^{a}$. ed., Rio de Janeiro, Agir, 1959. p. 251.
} 
extensão e quanto à forma dessa sistemática. Discute-se, por exemplo, quanto à extensão, até que ponto uma absoluta garantia de assistência pelo Estado pode afrouxar o estímulo ao esforço e ao trabalho. Quanto maior o desafio, maior o estímulo', escreve Toynbee". ${ }^{10}$ Caminhando nesta discussão na direção evitada por Gudin, percebemos que a obra de Hayek O Caminho da Servidão ${ }^{11}$ foi edificada para a crítica do Estado do bem-estar social - o welfare state - e inaugura a postura neoliberal. Sabiamente, a crítica realizada na pena gudiniana privilegiou, dentro da análise hayekiana, o que lhe interessava no momento, ou seja, os elementos que podiam ser utilizados como artilharia contra a visão marxiana da economia capitalista. Sendo assim, não ficou explicitada a posição contrária ao welfare state. Ela aparece na penumbra, garantindo que a carga maior recaísse predominantemente na concepção do filósofo alemão.

Para o autor, o capitalismo se põe como a realização do homem natural, que objetiva sua essência na economia de mercado — vista como também natural movida por uma lógica imanente, que tende ao auto-ajuste. A conclusão lógica do seu pensar revela a eternidade do sistema, cabendo, simplesmente, aperfeiçoá-lo, visto que sempre esteve presente no homem como elemento intrínseco de sua natureza. Consubstancia assim a visão a-histórica do capitalismo, não havendo fronteiras nessa forma de ser do econômico. É uma visão sobre a gestão do econômico que sustenta sua realização através da razão técnica - neutra segundo o pensamento neoclássico -, pois focaliza simplesmente a otimização dos fatores de produção, gerando o bem-comum para a sociedade, válido para todos os tempos.

$\mathrm{O}$ autor manteve os mesmos princípios para todas as lutas que travou. Corroborando o que já foi dito, lembramos sua controvérsia com Simonsen. Nela assinalou sua luta contra o intervencionismo, como já o fizera em 1943, na obra Para um Mundo Melhor. Continuou essa batalha contra as ideias cepalinas, tanto na figura de Raúl Prebisch como na de seus seguidores no Brasil. Lutou pela hegemonia da agricultura. Aceitou a industrialização somente subsumida àquele setor. No seu modo de ver, a indústria se punha mais como modernização do campo do que como um efetivo despertar de um setor autônomo e dinâmico. Era partidário do progresso social circunscrito a uma restrita ordem: a ordem do capital agrário associado ao capital estrangeiro-, hóspede bem-vindo, pois carregava o desenvolvimento e suas vantagens. Porta-voz do capital agrário, não poupou um só argumento para defendê-lo. Pensar o desenvolvimento era atuar na economia segundo a lógica daquele setor. Disputou, através da sua produção intelectual e da formação de quadros neoliberais, um espaço maior para a agricultura, reivindicando mais investimentos e criticando o espaço ocupado pelo setor industrial. Em nome da racionalidade econômica, calcada na imanência da alocação natural dos fatores de produção, clamava pela volta aos padrões do século XIX.

\footnotetext{
${ }^{10}$ Idem, Análise de Problemas Brasileiros, 2ª ed., Rio de Janeiro, Agir, 1965, pp. 130-1. (Grifo do autor)

11 Ver Perry Anderson, Balanço do Neoliberalismo. In Emir Sader, Pablo Gentili (org.), PósNeoliberalismo: as Políticas Sociais e o Estado Democrático, Rio de Janeiro, Paz e Terra, 1985, pp. 7-8.
} 
Assumiu cargos públicos, chegando a ministro da Fazenda. Teve uma breve gestão, inclusive por tentar pôr em prática o que pregava no plano de suas ideias: a mudança da liderança do setor industrial para o setor agrícola. Impossível, na então correlação de forças da década de 1950 no Brasil. Não era possível parar o trem da história e engatar marcha-à-ré. Não abrindo mão do seu projeto, resta-lhe a saída, como bem lembrou Roberto Campos, carregando sua bengala e o chapéu.

Esse interregno no poder sem sucesso não o fez esmorecer, continuou defendendo sua posição através de periódicos especializados da imprensa e junto a seus alunos. Enfrentou o auge do desenvolvimentismo dos anos 50 e $60 \mathrm{com}$ a mesma garra com que atacara Roberto Simonsen no passado. Viu, nesse período, a continuidade do caudilhismo iniciado na Era Vargas. O caudilhismo na política era a outra face do intervencionismo na economia. Ambos tinham de ser derrotados, pois eram os causadores do nosso atraso em todos os níveis. Vencer a barreira do subdesenvolvimento, para o autor, consubstanciava-se em derrotar essas duas formas de irracionalismo, que eram ramos da mesma árvore.

Em função do baixo nível de consciência existente no país, o autor defendia a recuperação das nossas raízes para vencer os obstáculos do irracionalismo. O povo não tinha formação educacional adequada para escolher os seus governantes; prova disso era o desarranjo que conheceu o país no período em que prevaleceram as eleições diretas pós-30. Durante a República Velha, felizmente, tínhamos a política dos governadores e conseguimos manter os maus governantes afastados do poder graças à sabedoria dos arranjos eleitorais. Depois do período getulista, tais acordos inviabilizaram-se e instaurou-se o caos.

O século XIX, mais uma vez, oferecerá a inspiração para superarmos os problemas da era do desenvolvimentismo: trata-se do Poder Moderador. Gudin evoca as Forças Armadas para incorporar esse poder e recolocar o país nos seus próprios pés. Vê no regime militar pós-64 a construção do capitalismo naturalista policiado e o remédio eficaz no combate ao caudilhismo antiliberal.

Defendeu o movimento de 31 de março de 1964 e, mesmo discordando em vários momentos de algumas de suas medidas - principalmente em relação ao planejamento - , reafirmou sua política econômica sempre em tom de conselho, chegando a afirmar ser o regime militar o coroamento de suas ideias. As discordâncias de Gudin não se apresentaram como oposição ao governo. Era, na realidade, o velho mestre relembrando os princípios do neoliberalismo. Como sempre, cumpria o papel de guardião do sistema.

Por seus adversários, foi visto como retrógrado, ligado a uma postura conservadora, defensor dos interesse alienígenas. Tal oposição se deu com Roberto Simonsen, com Celso Furtado e com os desenvolvimentistas em geral, unindo, do centro à esquerda, críticos à sua postura neoliberal. Com a mesma veemência com que lutou contra as ideias de Roberto Simonsen, esgrimou com Celso Furtado ${ }^{12}$,

\footnotetext{
12 Neste trecho de Furtado sobre Gudin, caracterizamos um dos momentos de suas contraposições: "Sem dúvida vivíamos uma fase de grandes transformações na economia do país, quiçá sem precedentes.
} 
protestando contra o discurso econômico que procurava uma explicação própria para o nosso atraso em relação aos pólos hegemônicos do capitalismo mundial. Bradava que existia somente uma teoria econômica que podia ser reconhecida como ciência. ${ }^{13}$

Acreditava que fora da teoria oficial (leia-se ortodoxa) representada por teóricos como Viner e Haberler, nada de novo fora criado. Era inadmissível para Gudin o conceito de inflação estrutural ou uma teoria econômica que não partilhasse da Lei das Vantagens Comparativas. ${ }^{14}$ Mesmo não indo fundo nas questões teóricas, segundo o parâmetro dos principais centros mundiais onde o debate acontecia, registrou sua oposição a qualquer visão que fugisse do pensamento tradicional. Tanto o marxismo como as teorias terceiromundistas conheceram sua ira implacável, pois negavam o conceito de capitalismo naturalista.

Por outro lado, ganhou fervorosos adeptos que, mesmo nos dias de hoje, lembram a sua figura como um farol que orienta a defesa do capitalismo; esses adeptos tanto podem ser os seus contemporâneos e seguidores na Fundação Getúlio Vargas, como representantes do neoliberalismo de uma maneira geral. Roberto Campos cita-o como o exemplo maior da coerência na defesa do sistema. E mais, considera-o o grande vencedor, a longo prazo, na disputa economia de mercado x planejamento.

A sua figura, como o grande idealizador do IBRE (Instituto Brasileiro de Economia da FGV/RJ), assim como das publicações que derivaram daquele organismo, é ponto de honra na história daquela instituição. História que se confunde com a idealização dos cursos de Economia criados no país a partir da década de 40. Gudin militou para imprimir, nos mesmos, a marca da lógica do capital. Lutou e venceu a batalha de manter um currículo próprio para o curso de Ciência Econômica, separado do curso de Administração de Empresas e de Contabilidade, vinculando a necessidade dessa separação à criação de quadros especialistas em economia para o comando da produção, defendendo essa forma como pressuposto para o progresso do país. Coroou sua vitória com a redação do decreto-lei de 22 de setembro de 1945, que regulamentou o curso de Ciência Econômica e foi pro-

\footnotetext{
Já me referi ao fato de que o Brasil acumulara um considerável atraso dentro da própria América Latina. O pensamento dominante, como o do Prof. Gudin, não se surpreendia com isso, pois estava imbuído do determinismo geográfico que estivera em moda no século XIX. A Argentina, dizia-se, tinha melhor clima e melhores solos que nós. Ora, não se necessitava de muita ciência, àquela altura do século XX, para perceber que as causas de nosso atraso tinham raízes históricas, podendo ser removidas pela sociedade. Certo: as circunstâncias em que se dão as mudanças que conduzem ao desenvolvimento no curso da História, nem sempre são fáceis de perceber, menos ainda pelos contemporâneos. Mas era evidente que a Grande Depressão obrigara o Brasil a mudar de rumo aos trancos e barrancos, descobrindo as potencialidades do mercado interno”. Furtado, C. A Fantasia Organizada. $5^{\text {a }}$ ed., Rio de Janeiro, Paz e Terra, 1985, p. 160.

${ }^{13}$ Ver sobre essa discussão: Hirschman, A. O. A Economia como Ciência Moral e Política, São Paulo, Brasiliense, 1986.

${ }^{14}$ Ver Adam Smith para a Lei das Vantagens Comparativas in A Riqueza das Nações, Livro IV e D. Ricardo para As Vantagens Comparativas Relativas in Princípios de Economia Política e Tributação, Cap. VII - Sobre o Comércio Exterior.
} 
jetado desde o início dos anos 40, juntamente com a pena de Octávio G. de Bulhões e Maurice Byé. ${ }^{15}$ Esta regulamentação foi um dos momentos do debate nacional entre as diferentes forças que interagem no capitalismo e pensam a teoria que busca explicar e dominar sua mecânica de funcionamento. A disputa estava, agora, mais organizada na academia, com sua influência garantida dentro e fora dos seus muros, sendo, porém, mais um dos agentes na formulação dos conceitos que fertilizavam a luta ideológica na sociedade como um todo.

Todavia, o debate não acabou, assim como não começou com Gudin. As contradições inerentes ao ser histórico do capitalismo - demarcadas pelos diferentes interesses dos agentes sociais em disputa no processo de construção e reprodução das condições da existência material- estiveram presentes desde a sua gênese, assim como permanecem até os dias atuais. Essa disputa faz parte da lógica imanente do capitalismo e nela Gudin foi mais um dos seus representantes neoliberais. Porém, conquistou seu lugar como ponto de referência, sendo até hoje mencionado por seus scgu idores.

Tendo em vista todas essas colocações, torna-se um grande desafio dar conta de um autor como Eugênio Gudin. ${ }^{16}$ Isso se deve a alguns motivos; não tanto quanto à complexidade da obra do ponto de vista da teoria econômica ${ }^{17}$, pois o

\footnotetext{
${ }^{15}$ Foi em agosto de 1944 de volta da Conferência de Bretton Woods que "Eugênio Gudin visita a Faculdade de Economia da Universidade de Harvard, em companhia de Otávio Gouveia de Bulhões, onde discute o projeto da Faculdade de Economia do Rio de Janeiro (que se transformará na Universidade do Brasil, hoje Universidade Federal do Rio de Janeiro). O resultado da visita é relatado em carta ao ministro, enviada de Chicago: 'Escrevi na pedra o programa e o projeto de currículo que lhe recomendamos, para submetê-lo à crítica de todos e para receber sugestões dos mestres. Tenho a satisfação de comunicar-lhe que depois de fazerem várias perguntas e de pedirem esclarecimentos, todos os professores de Harvard acharam o programa excelente, dizendo que nada havia a modificar". Schwartzman, S. et alli. Tempos de Capanema. Rio de Janeiro e São Paulo, Paz e Terra e EDUSP, 1984, p. 224. A referência feita é ao ministro Gustavo Capanema da Educação no governo do presidente Getúlio Vargas. Foi durante esse encontro que Gudin reforçou o seu ponto de vista de criar o curso de ciências econômicas separado das outras áreas das ciências administrativas: "Perguntam-lhes (aos professores de Harvard) também sobre a conveniência ou não de separar as duas faculdades, a de economia e a de administração. Eles nos levaram à janela para mostrar-nos, do outro lado do rio, a faculdade de administração, (... ) e nos recomendaram que se não tivéssemos um rio abríssemos um canal (... ) para separar as duas faculdades”. Idem, ibidem

${ }^{16}$ Sobre a importância de Eugênio Gudin, ver a resenha que o Prof. Dr. Eleutério F. da Silva Prado fez sobre o livro que deu origem a este texto: Eugênio Gudin: Capitalismo e Neoliberalismo. São Paulo, Bienal/EDUC, 1996; publicada na Revista de Economia Política, vol. 17, nº 3 (67) jul./set. São Paulo, Editora 34, 1997, pp. 148-9.

${ }^{17}$ Seguindo a postura do filósofo hungáro G. Lukács na análise marxiana, temos que a complexidade, assim como a profundidade da contribuição teórica de um determinado autor está circunscrita à sua possibilidade efetiva de realizar a concreção analítica. Não basta dominar vários campos do saber para atingir essa profundidade. Na crítica da compartimentação da sociologia e da economia como "ciências autônomas", Lukács explicitou claramente os seus pressupostos ontológicos - que, para o autor, vão além da postura gnosiológica no campo da análise da ideologia, não deixando margem para dúvidas: "Essa separação liga-se a profundas crises da economia burguesa, nas quais transparece claramente a base social da sociologia: por um lado, temos a dissolução da escola de Ricardo na Inglaterra, quando se começam a extrair consequências socialistas da teoria do valor-trabalho dos clássicos; e, por outro,
} 
autor é muito mais um propagandista do que um inovador. Por exemplo, ele cumpre o sofisticado papel de dar corpo às ideias neoliberais no intrincado cenário caboclo, marcado pelo atraso econômico e político; e é justamente esse atraso que cria o chão social adequado para as suas ideias; sem sofisticação teórica, porém, com refinamento ideológico. Nisso ele se sai muito bem; e, usando a vulgarização do discurso econômico (vista como um talento, pois o torna "acessível"), penetra a opinião pública e cria o espaço almejado no plano das ideias, para o setor que representa, ganhando reconhecimento internacional, tornando-se um "embaixador" do neoliberalismo brasileiro.

O atraso da realidade brasileira cria a necessidade de uma "figura teórica" como Eugênio Gudin; e o seu maior valor é ter respondido a essa "missão" com uma produção sem precedentes na história do pensamento econômico brasileiro, na vertente neoliberal. Nesse sentido, foi um dos principais ideólogos do século XIX na história brasileira. Lúcido do seu papel, não mediu esforços para concretizá-lo.

Estudar o seu pensamento faz-se necessário em função do papel que cumpriu e cumpre a sua obra. A força de suas ideias vem do poder da reação dos setores que temem rediscutir o lugar do Brasil no mundo dominado pela lógica do capital. Relembrar Gudin, reiterando os princípios que sempre defendeu, é lutar para perpetuar e aprofundar a atual subsunção da economia brasileira no mercado internacional. A defesa do neoliberalismo converge para a defesa da permanência da inserção mundial do capitalismo brasileiro nos moldes atuais, dependente dos centros hegemônicos do capitalismo monopolista.

Neoliberalismo: conceito negado pelos setores que explicitamente se identificam com a lógica do trabalho, incômodo para alguns, que optam pelo conforto do discurso moderado, e endeusado por outros que, como Gudin, tomam-no como bandeira de luta na defesa do sistema natural de produção: a economia de mercado. O rigor metodológico perseguido na nossa pesquisa e na construção da análise sobre o pensamento do economista neoliberal obrigou-nos a fazer um recorte circunscrito à produção do autor, procurando o aprofundamento do objeto investigado. Existe outra justificativa para as características de nossa análise que deve ser acoplada ao que já foi dito e que também transparece neste trabalho. Se de um

temos a dissolução do socialismo utópico na França, onde se começa a buscar - ainda que somente ao nível das tentativas - o caminho da sociedade para o socialismo, o que não havia constituído objeto de investigação por parte de Saint-Simon e de Fourier. Essas duas crises - e, sobretudo, a resolução de ambas através do surgimento do materialismo histórico e da economia política marxista - põem fim à economia burguesa no sentido dos clássicos, ou seja, no sentido de ciência fundamental para o conhecimento da sociedade. Por um lado, nasce a economia burguesa vulgar e, mais tarde, a chamada economia subjetiva, uma disciplina particular de caráter extremamente especializado, que renuncia desde o início a explicar os fenômenos sociais e considera como sua principal tarefa a de fazer desaparecer da economia política a questão da mais-valia; por outro lado, nasce a sociologia enquanto ciência do espírito desvinculada da economia”. Lukács. Coleção Grandes Cientistas Sociais organizada por José Paulo Netto, São Paulo, Ática, 1971. O extrato acima pertence à obra A destruição da razão, publicada em 1954; cabe frisar que essa publicação é uma das obras mais discutidas do filósofo marxiano, em razão da contundência de seus desenvolvimentos, formalmente marcados pelas condições ideológicas da Guerra Fria. 
lado perseguimos a máxima determinação possível do universo categorial do autor e explicitamos a sua função social nos cenários nacional e internacional, de outro, a nossa pesquisa sinalizou que em função das características da obra do autor marcada pela ausência de profundidade teórica dentro da ciência econômica -, não há propriamente seguidores de Gudin e sim sucessores. O destaque é o economista Roberto Campos, que não reproduziu a produção intelectual gudiniana enquanto matriz teórica, mas sim apóia-se no seu exemplo neoliberal. Isso é bem ilustrado na controvérsia que ambos travaram sobre a questão programação x planejamento e, especialmente, na postura de um e de outro enquanto ocupantes de cargos no aparelho de Estado. Não existe uma teoria gudiniana como referência e sim uma postura neoliberal a ser aludida, como disse Chacel: "Gudin como professor fez escola. Escola que acredita na liberdade do homem, como condição essencial para o processo de escolha e da decisão econômica. Que é reticente diante da proposta híbrida de um economia de mercado compatível com um planejamento fortemente centralizado na ação do Estado. Nem todos, obviamente, seguem a sua doutrina e dão ao fenômeno monetário o poder explicativo que Gudin lhe confere. Mas todos, sem exceção, que conviveram e convivem com Gudin, dentro e fora de uma sala de aula, retiraram e retiram do seu convívio uma grande lição. Lição de Vida”. ${ }^{18}$ Aliás, podemos reconhecer nas palavras do próprio Gudin a consciência de

\footnotetext{
${ }^{18}$ Julian M. Chacel, in Eugênio Gudin Visto por seus Contenporâneos, Rio de Janeiro, Fundação Getúlio Vargas, 1979, p. 35. Outros autores, ao realçarem outras nuanças da obra gudiniana, também registraram essa característica própria ao discurso do pensador neoliberal brasileiro, ou seja, não ter aprofundado a teoria econômica, mas sim ter cumprido o papel de divulgador das ideias econômicas que refletiam a sua visão de mundo. Para efeito de ilustração, citaremos dois comentaristas: primeiramente, lembramos o Prof. Marcelo de Paiva Abreu, ao se referir à controvérsia entre Gudin e Simonsen: "Em 1945, Gudin reproduz o parecer no qual, no âmbito da Comissão de Planejamento Econômico (...), criticara pesadamente o documento apresentado pelo conselheiro Roberto Simonsen ao Conselho Nacional de Política Comercial e Industrial sobre a planificação e o desenvolvimento industrial (... ). Essa controvérsia é, na verdade, singularmente desinteressante do ponto de vista estritamente econômico". Marcelo de Paiva Abreu, "Contribuições de Eugênio Gudin ao Pensamento Econômico Brasileiro”, in Literatura Econômica, vol. 6, n 4 outubro de 1984, p. 628. Em seguida, temos o Prof. Ricardo Bielschowsky que, com maestria, retratou adequadamente o lugar do pensamento neoliberal de Gudin no quadro teórica nacional: “A fonte básica para detectar sua base teórica é seu livro-texto Princípios de Economia Monetária, que o próprio autor tratava como uma espécie de manual de referências teóricas para suas análises concretas da economia do país. Vale notar, a respeito do livro, que sua estrutura retrata com fidelidade as características do envolvimento de Gudin com a ciência econômica. Gudin não era o que se convencionou chamar de economista teórico. Foi um economista aplicado por excelência. Buscava na teoria econômica o instrumental necessário para o entendimento de uma série de questões reais que o inquietavam, como a inflação, ciclos econômicos, comércio internacional para países subdesenvolvidos, e assim por diante. E o fazia com o objetivo prático de entender as possibilidades de inflenciar essas questões através de políticas econômicas e de se entender o sentido e o alcance das mesmas. Não teve, por exemplo, a preocupação de tratar teoricamente os princípios liberais, o que se reflete mesmo em seu livro- texto. Essa sua principal obra acadêmica mantém uma clara inclinação para a orientação da política econômica, que sugere, quando se considera a carreira do autor, uma vasta 'declaração de princípios de economia monetária', de um candidato a banqueiro central ou ministro da Fazenda”. Ricardo Bielschowsky, Pensamento Econômico Brasileiro: o Ciclo Ideológico do Desenvolvimentismo, Rio de Janeiro, lpea/Inpes, 1988, p. 50.
} 
que a sua contribuição, para as reflexões sobre teoria econômica, estava restrita ao papel de divulgador da nuança tradicional: "Nunca construí 'modelo econômico' algum, nem formei 'escola' alguma. O que procurei fazer foi tentar esclarecer o que era confuso ou corrigir o que me parecia errado". ${ }^{19}$

Nessa direção, analogamente, podemos afirmar que o mestre dos economistas neoliberais representou, no cenário intelectual nacional, o mesmo papel que Giannetti da Fonseca descreve para o seu sucessor, Roberto Campos: "Eu admiro Roberto Campos. É um homem público notável, de uma extraordinária coragem, por ter defendido posições impopulares em momentos em que a pressão era fortíssima. Qualquer país só pode ser grato por ter um homem público do porte e do preparo dele. Por outro lado, ele é mais um divulgador e um expositor do que propriamente um pesquisador, alguém que busca o conhecimento que não existe. Ele é realmente muito habilidoso na comunicação, na formulação, mas não enxergo no Roberto Campos o compromisso com a busca do conhecimento novo, um trabalho original de pesquisa, de pensamento, de busca. Ele é mais propaganda, divulgação, e faz isso com arte, com maestria, mas num plano diferente. É um outro tipo de inserção no mundo das ideias". ${ }^{20}$

É preciso frisar que o economista carioca aglutinou ao seu redor adeptos do neoliberalismo de diferentes matizes. Não chegou a formar uma escola teórica de economia, nem sequer com relação à sua postura diante da política monetária. Mas sim, criou um escudo de aço em torno de seu nome para a defesa do capitalismo liberal, onde abrigou e até hoje abriga vários nomes.

Pudemos perceber que o economista carioca é muito mais aludido do que conhecido, aumentando-se, com isso, a necessidade do seu desvelamento. É evocado como o símbolo do neoliberalismo brasileiro, mas, curiosamente, é pouco estudado em função do alarde que o seu nome produz; portanto, ainda não decifrado para a grande maioria, fica muitas vezes somente uma referência vazia à sua obra. Que todos saibam o que realmente ele defendeu. E que Gudin seja evocado ou criticado em função do que produziu e não do que se possa dizer a seu respeito.

\footnotetext{
${ }^{19}$ Esta citação de Gudin foi feira, originalmente, por Glycon de Paiva, na Apresentação que fez ao livro O Pensamento de Eugênio Gudin, Rio de Janeiro, Fundação Getúlio Vargas, p. V. Paiva cita o mestre carioca, dando-nos, através das suas próprias palavras, a verdadeira dimensão do papel que ele representou.

${ }^{20}$ Ciro Biderman, Luis Felipe, L. Cozac e José Marcio Rego, Conversas com Economistas Brasileiros, São Paulo, Editora 34, pp. 397-8
} 